\title{
OPEN RADIATION: a collaborative project for radioactivity measurement in the environment by the public.
}

\author{
Jean-François Bottollier-Depois ${ }^{1, *}, E$. Allain ${ }^{2}, G$. Baumont ${ }^{1}, N$. Berthelot ${ }^{3}, I$. Clairand ${ }^{1}, C$. Couvez ${ }^{1}, G$. \\ Darley $^{1}, B$. Henry ${ }^{3}, T$. Jolivet ${ }^{3}, P$. Laroche ${ }^{4}, A$. Lebau-Livé ${ }^{1}, V$. Lejeune ${ }^{1}, J$. Miss ${ }^{1}, W$. Monange ${ }^{1}, F$. \\ Quéinnec $^{1}, Y$. Richet ${ }^{1}, C$. Simon ${ }^{5}, F$. Trompier ${ }^{1}, F$. Vayron ${ }^{1}$ \\ 1: IRSN, Institute for radiological Protection and Nuclear Safety, 92262 Fontenay-aux-Roses, France \\ 2: IFFoRME, Institut Français des Formateurs Risques Majeurs et protection de l'Environnement, 9 rue Jacques Louvel- \\ Tessier, 75010 Paris, France \\ 3: Planète Sciences, 16, place Jacques Brel, 91130 Ris-Orangis, France \\ 4: Agoralogie, 36 boulevard de la Bastille, 75012 Paris, France \\ 5: UPMC, Pierre and Marie Curie University, 4, place Jussieu, 75005 Paris, France
}

IRSN/PRP-HOM, France

\begin{abstract}
After the Fukushima accident, initiatives emerged from the public to carry out themselves measurements of the radioactivity in the environment with various devices, among which smartphones, and to share data and experiences through collaborative tools and social networks. Such measurements have two major interests, on the one hand, to enable each individual of the public to assess his own risk regarding the radioactivity and, on the other hand, to provide "real time" data from the field at various locations, especially in the early phase of an emergency situation, which could be very useful for the emergency management.
\end{abstract}

The objective of the OPENRADIATION project is to offer to the public the opportunity to be an actor for measurements of the radioactivity in the environment using connected dosimetric applications on smartphones. The challenge is to operate such a system on a sustainable basis in peaceful time and be useful in case of emergency. In "peaceful situation", this project is based on a collaborative approach with the aim to get complementary data to the existing ones, to consolidate the radiation background, to generate alerts in case of problem and to provide education \& training and enhanced pedagogical approaches for a clear understanding of measures for the public. In case of emergency situation, data will be available "spontaneously" from the field in "real time" providing an opportunity for the emergency management and the communication with the public....

The practical objective is i) to develop a website centralising data from various systems/dosimeters, providing dose maps with raw and filtered data and creating dedicated areas for specific initiatives and exchanges of data and ii) to develop a data acquisition protocol and a dosimetric application using a connected dosimeter with a bluetooth connection.

This project is conducted within a partnership between organisms' representative of the scientific community and associations to create links with the public.

"Corresponding author: jeanfrancois.bottollier@,irsn.fr

(C) The Authors, published by EDP Sciences. This is an open access article distributed under the terms of the Creative Commons Attribution License 4.0 (http://creativecommons.org/licenses/by/4.0/). 


\section{OPENRADIATION: a collaborative project for radioactivity measurements in the environment by the public}

Jean-François BOTTOLLIER-DEPOIS (IRSN)

On behalf of the group

ICRS13 - RPSD2016 4 October 2016

E Allain ${ }^{2}$, G Baumont ${ }^{1}, \mathrm{~N}$ Berthelot ${ }^{3}$, I Clairand ${ }^{1}$, C Couvez ${ }^{1}$, G Darley ${ }^{1}$, B Henry ${ }^{3}$, T Jolivet ${ }^{3}$, P Laroche ${ }^{4}$, A Lebau-Livé ${ }^{1}$, V Lejeune ${ }^{1}$, J Miss ${ }^{1}$, W Monange ${ }^{1}$, F Quéinnec ${ }^{1}$, Y Richet ${ }^{1}$, C Simon ${ }^{5}$, F Trompier ${ }^{1}$, F Vayron ${ }^{1}$ ${ }^{1}$ IRSN, Institute for Radiological Protection and Nuclear Safety, 92262 Fontenay-aux-Roses, France

2 IFFoRME, Institut Français des Formateurs Risques Majeurs et protection de l'Environnement, 75010 Paris, France

3 Planète Sciences, 91130 Ris-Orangis, France

${ }^{4}$ Agoralogie, 75012 Paris, France

${ }^{5}$ UPMC, Pierre and Marie Curie University, 75005 Paris, France 
"Radiation dose to researchers:

- a quantitative value of the physical agent

Radiation dose to residents:

- a quantitative value of their everyday life

- Working together to support their self-help actions is the only way to help them to gain self confidence. Only then science has some meaning to people

- Provide the most accessible information

- Offer the possibility to each person to assess is own risk by doing himself measurements" 


\section{The context...}

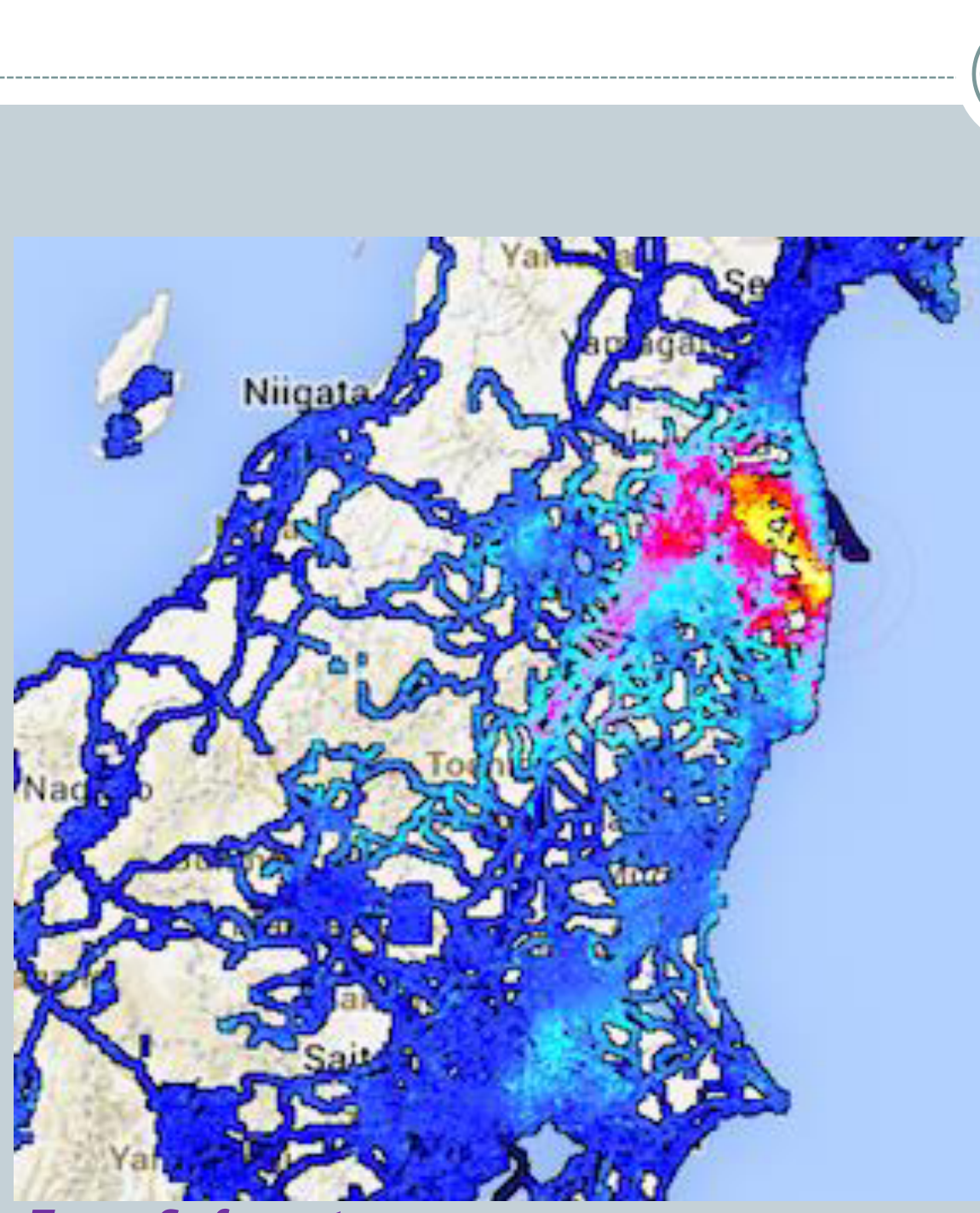

From Safecast

- After the Fukushima accident, dosimetric applications dedicated to the public appeared to realise geo-localised measurements of the radioactivity in the environment

- Today, such systems are used at a relatively large scale, in particular by the Japanese population, providing an interesting feedback 


\section{... the context}

In case of emergency situation: data from the population using various dosimetric applications

(:) Data coming from the field in "real time"

(): Data provided in mass...

(:) ... but with a confident level not always very high!

(2) Important solicitation of authorities/experts by the population foreseen In « peaceful time »: data provided by the public in the frame of a collaborative approach \& citizen science

() Data coming mainly from a "motivated" public: few\% of the general population interesting by the topic, specific projects/studies (students, associations...)

: Data with a confident level to be checked

: False alarms may be generated 


\section{What is the interest for the scientific community?}

"Peaceful time"

- Offer to the public the possibility to contribute. to a citizen science project on the radioactivity measurement

- Get complementary data to the existing ones and consolidate the background reference valües

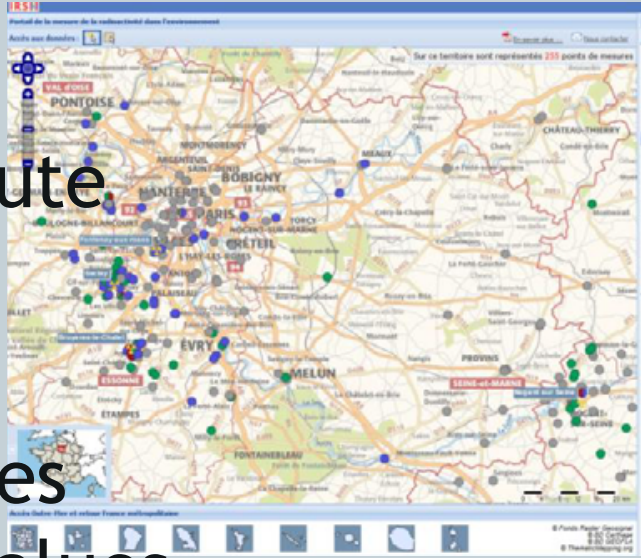

- Provide alerts in case of problem

Emergency situation

- Get data contributing to the management of emergency situations (decision making, complementary to the existing measurements and the dispersion models...)

- Provide an opportunity to communicate with the public 


\section{What is the interest for the public?}

Collective use: "I perform measurements and send data for a collective use and to exchange information"

- In normal situation, by participating to a collaborative project / citizen science

- In case of emergency, by providing spontaneously data useful for the stakeholders involved in the crisis management and the population

Personal use: "I perform measurements to assess my own risk, especially in case of emergency situation"

These different modes have to be taken into account to develop an application for the public 


\section{What are the challenges?}

Operate the system on a sustainable basis in peaceful time and useful in case of emergency situations

\section{"Peaceful time"}

- Set up a pedagogic and sustainable system used by the public

- Get data robust enough in complement to the background reference values

- Manage alerts in case of positive measurements

- Operate a collaborative website

Emergency situation

- Get data robust enough to contribute to the management of emergency situations (decision making...)

- Communicate with the public

- Operate the website in "crisis" mode 


\section{The OPENRADIATION project}

Collaborative project (open data \& source) to measure the radioactivity in the environment involving the public and using connected dosimetric applications on smartphones

\section{Develop an internet site}

- Centralise data from various systems/dosimeters

- Provide dose maps with raw and "filtered" data

- Create dedicated areas for projects and information exchange

Develop a dosimetric application

- Develop a connected dosimeter using bluetooth (GM...)

- Develop a smartphone application to collect and transmit data 


\section{An open partnership}

IRS [N]

INSTITUT

DE RADIOPROTECTION

ET DE SÜRETE NUCLEAIRE

Institute for

Radiological Protection and Nuclear Safety

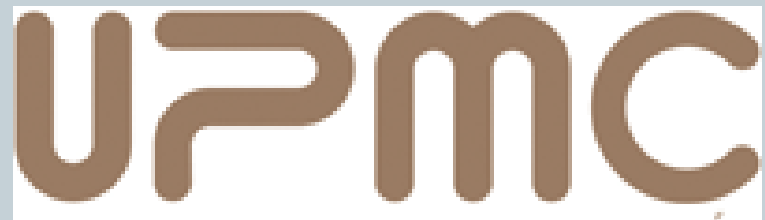

IQ⿴囗十 SORBONNE UNIVERSITÉS

University Pierre and Marie Curie

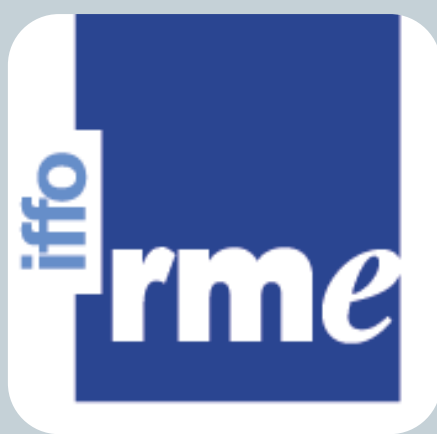

Association involved in E\&T for crisis management

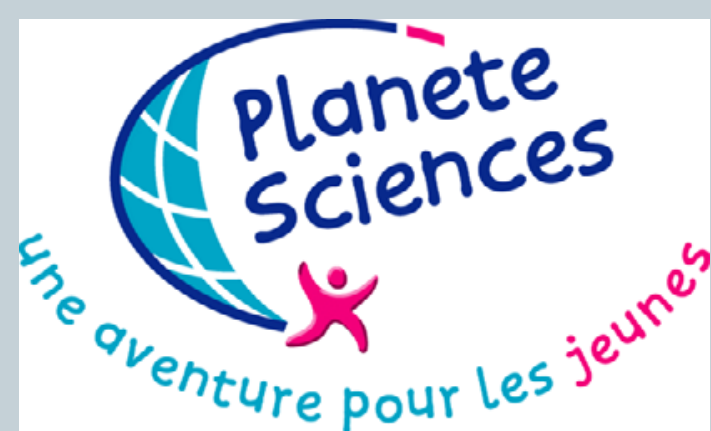

Association involved citizen science for young people

To be enlarged in the future:

Associations, academic partnerships, public representatives... 


\section{The website... his architecture}

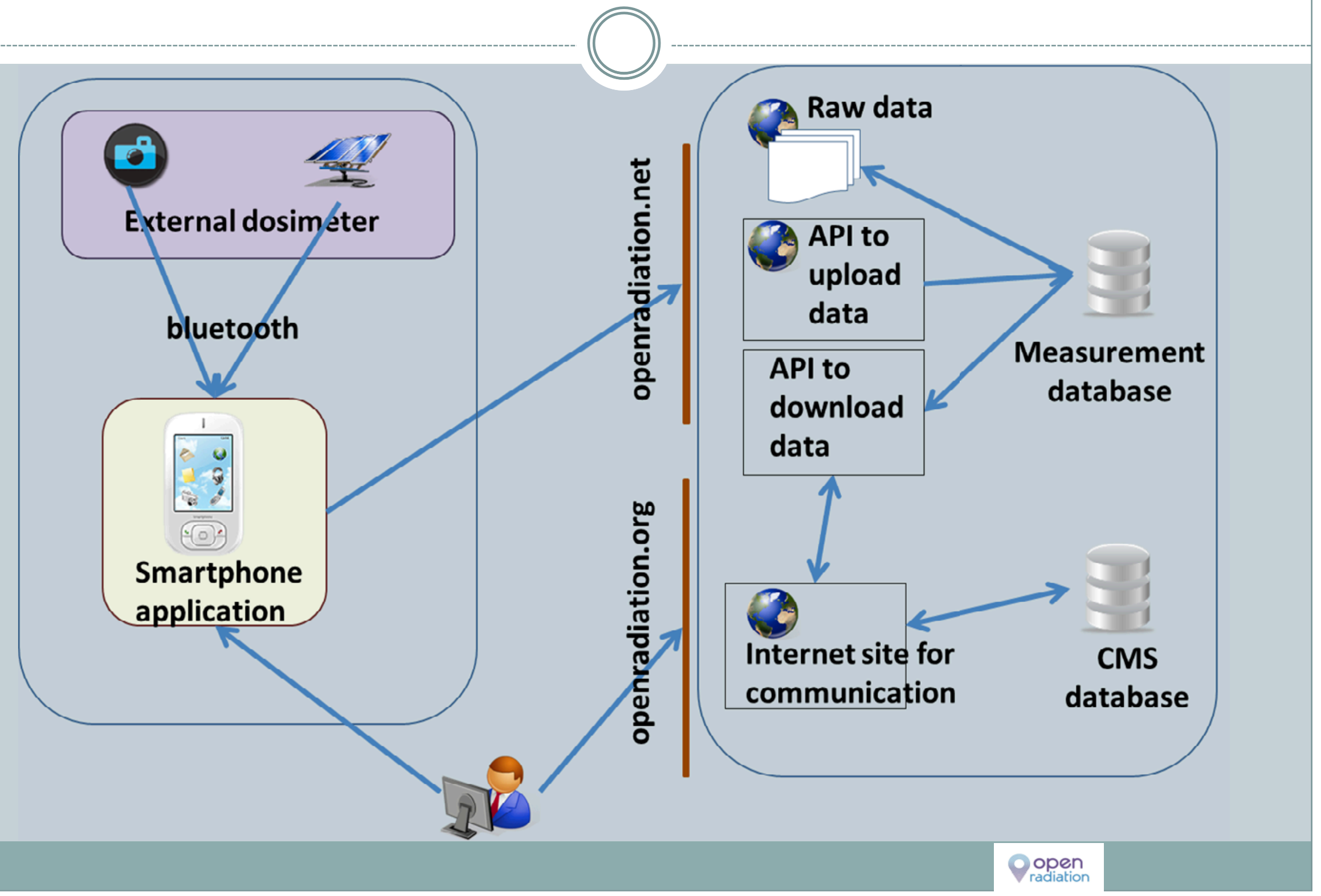




\section{The website... under commissioning}

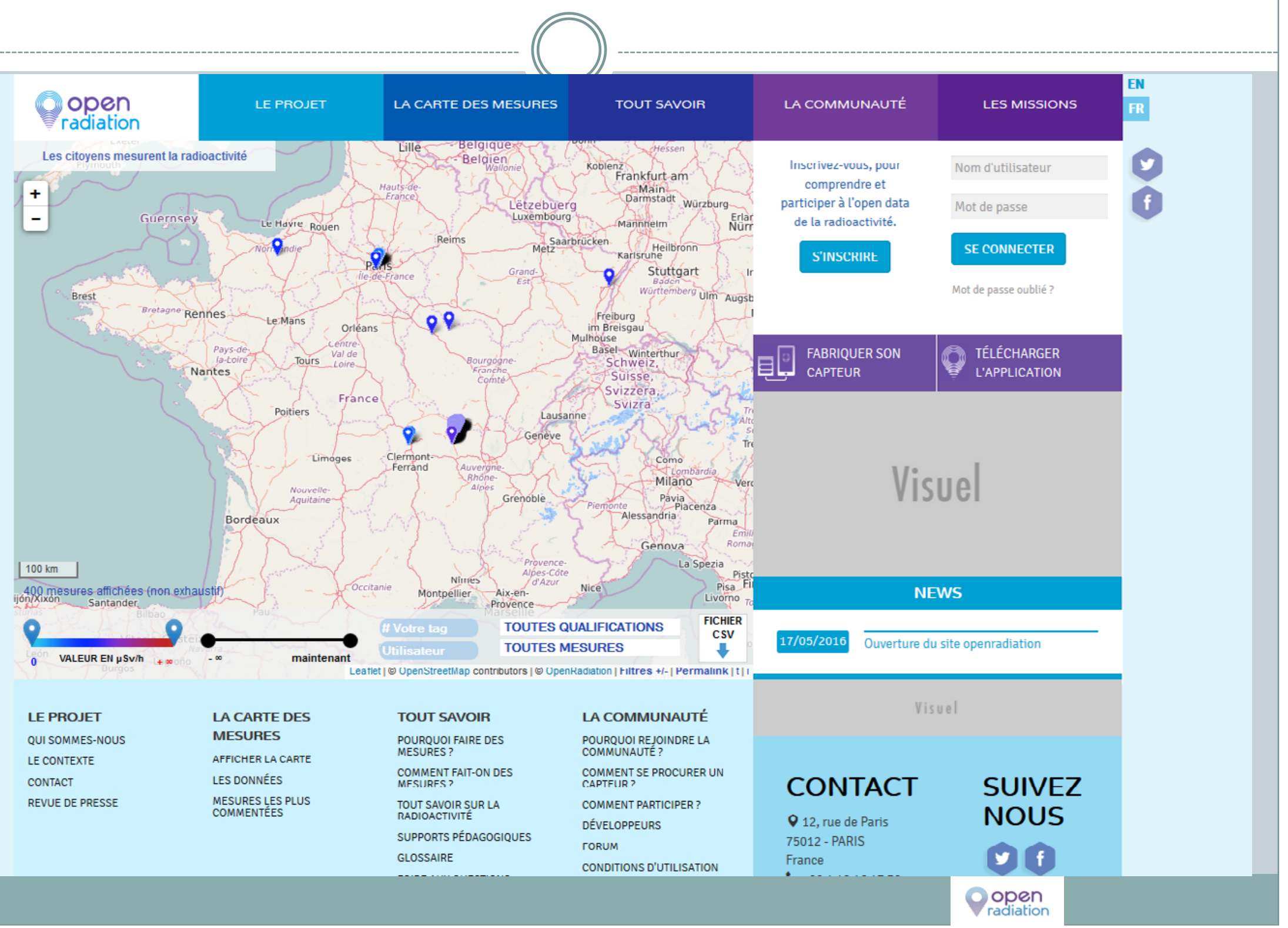




\section{... the website}<smiles>C1=CC=CC=CC=1</smiles>

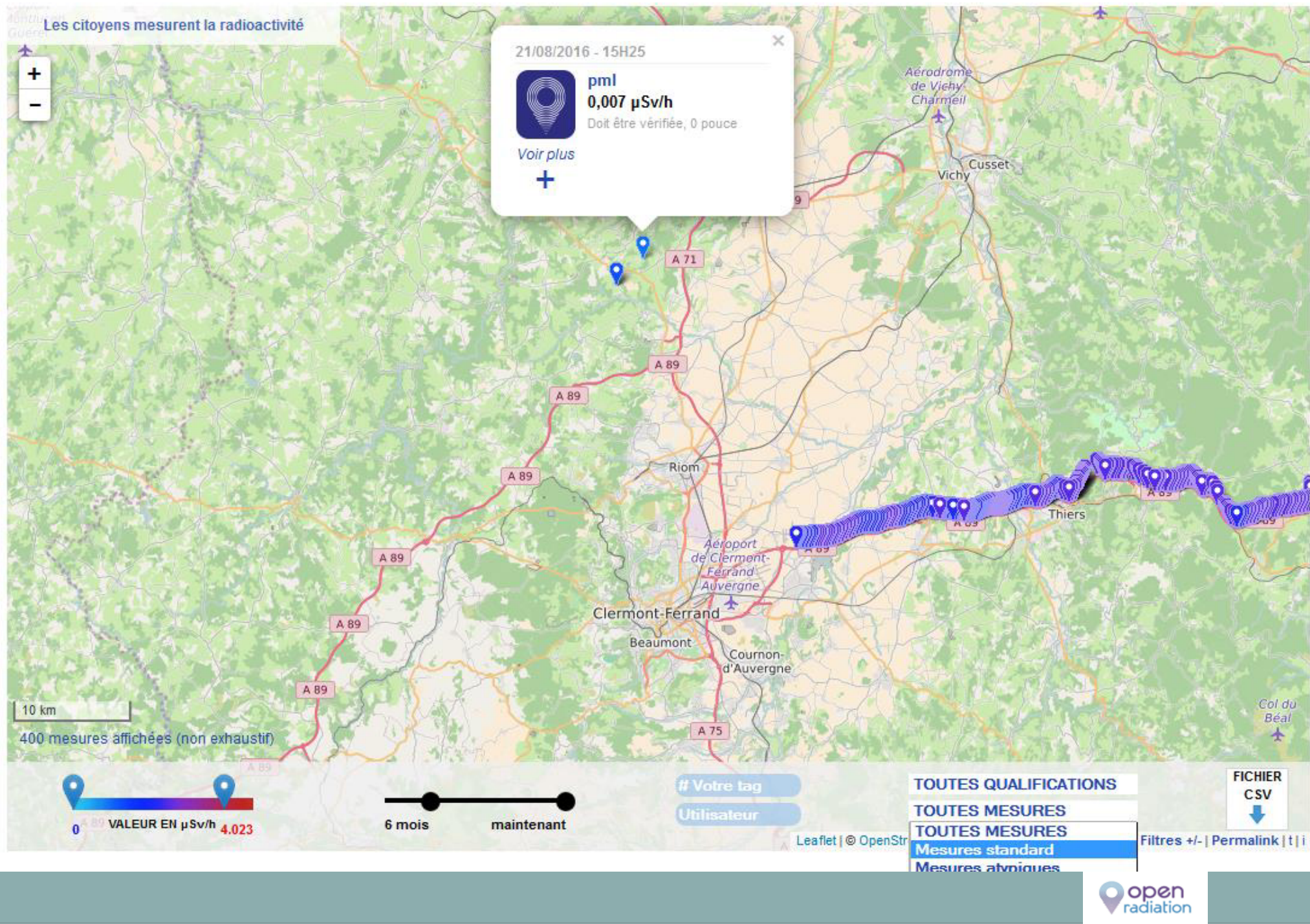




\section{... the website}

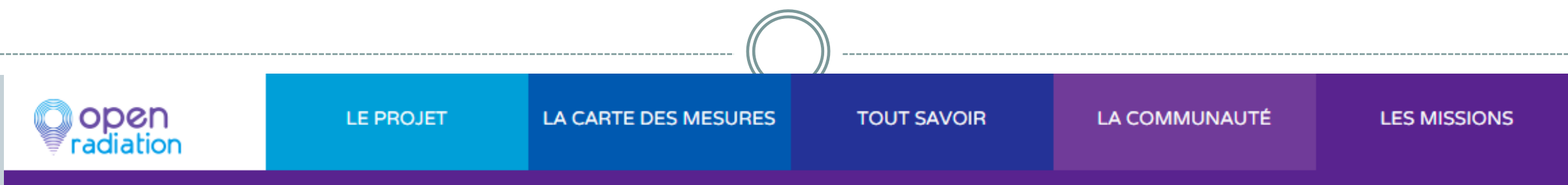

\section{LES MISSIONS EN COURS}

Les missions / Les missions en cours

\section{Mission}

La radioactivité en Auvergne

Dans le cadre d'un TPE, utiliser un radiamètre, comprendre l'unité de mesure, découvrir le fond radiologique local et émettre des hypothèses sur l'origine de la radioactivité ambiante.

Du radon dans ma maison?

Appréhender la mesure de la radioactivité à partir d'un cheminement pédagogique sur le Radon et en utilisant le dosimètre canary.

Intégrer la mesure dans une démarche pédagogique sur la radioactivité, qui se décline selon quatre entrées : - faune/flore, - activité nucléaire, - mémoire, - vivre à proximité. Placer les jeunes dans une situation d'investigation sur la radioactivité. Dans un travail d'enquête, mobiliser des ressources variées : interview d'acteurs, articles de presse, ressources internet etc..... Comprendre et contribuer à une cartographie de la radioactivité dans l'environnement

\begin{tabular}{l|l|l|}
$\begin{array}{l}\text { Chef de } \\
\text { mission }\end{array}$ & Date de fin & Adhésion \\
\hline $\begin{array}{l}\text { root- } \\
\text { user }\end{array}$ & $06 / 06 / 2016$ & $\begin{array}{l}\text { S'abonner } \\
\text { au groupe }\end{array}$ \\
\hline & $17 / 06 / 2016$ & $\begin{array}{l}\text { S'abonner } \\
\text { au groupe }\end{array}$ \\
\hline $\begin{array}{l}\text { root- } \\
\text { user }\end{array}$ & $30 / 06 / 2017$ & $\begin{array}{l}\text { S'abonner } \\
\text { au groupe }\end{array}$ \\
\hline
\end{tabular}




\section{The Open Geiger dosimeter}

- GM counter (silicon diode in the future)

- Bluetooth connection

- Application on iPhone, Android and tablet - Collaboration UPMC/IRSN/Planète Science

- 2 versions: "kit" and "packaged"
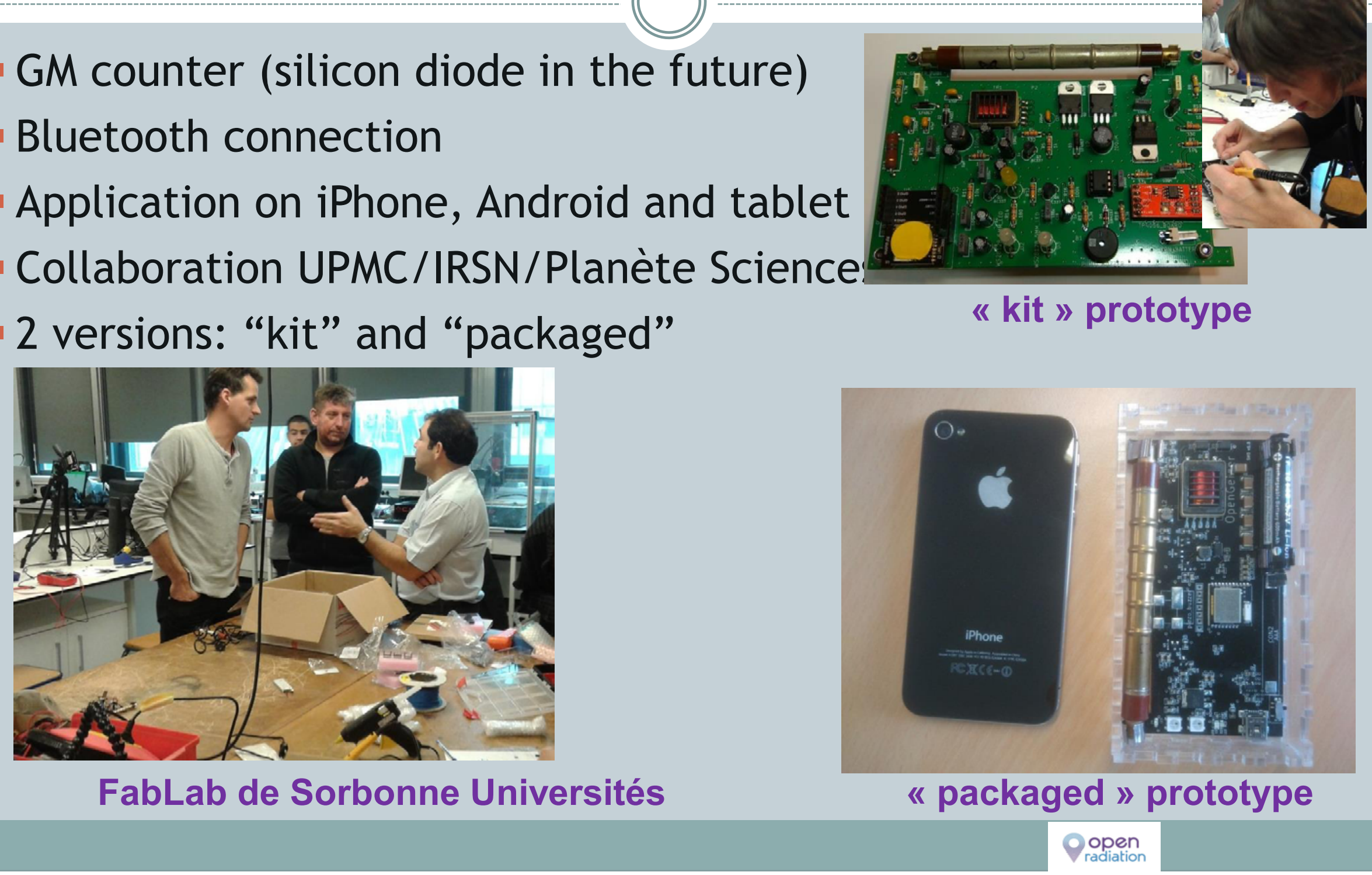

FabLab de Sorbonne Universités

« packaged » prototype 


\section{The smartphone application}

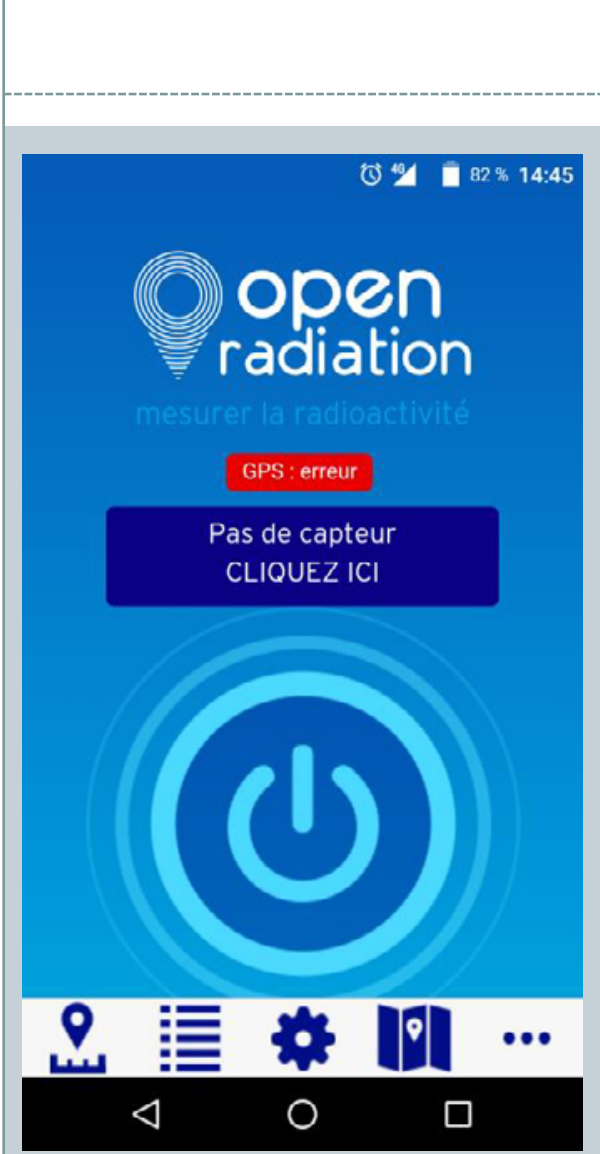

Home page

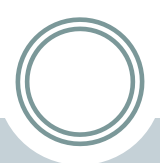

Measurement

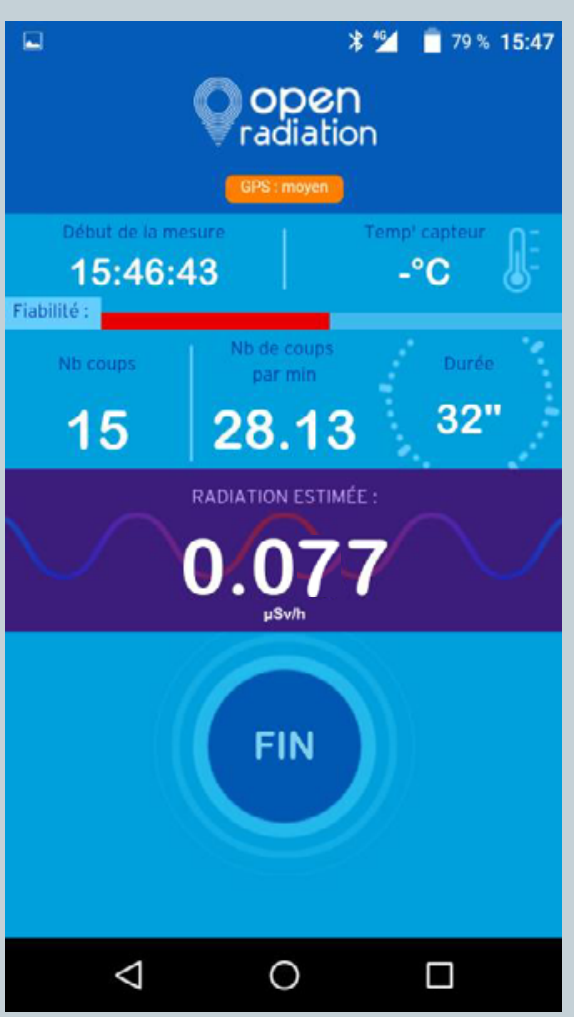

$$
\begin{aligned}
& \text { "Poor" } \\
& \text { statistic }
\end{aligned}
$$

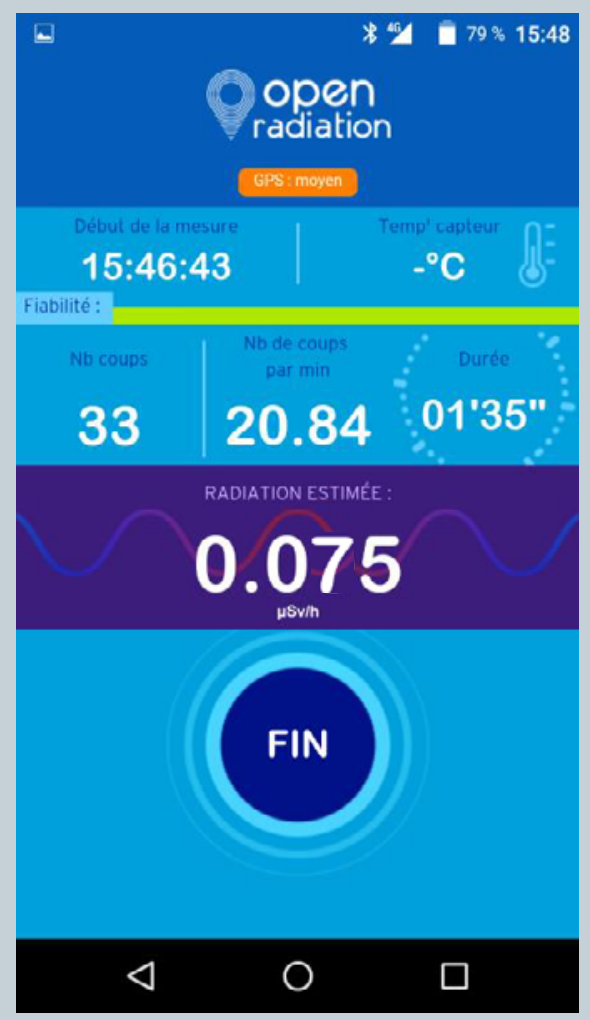

"Acceptable" statistic

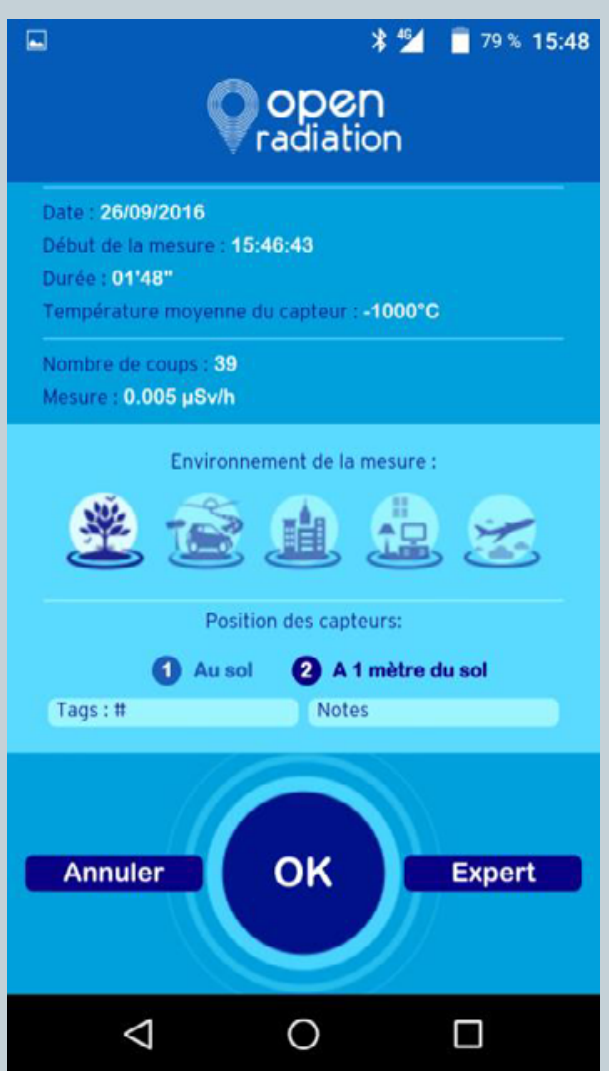

Metadata 


\section{Other dosimeters}

Other dosimeters can be used

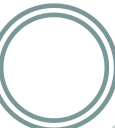
using a specific interface or enter manually measurements

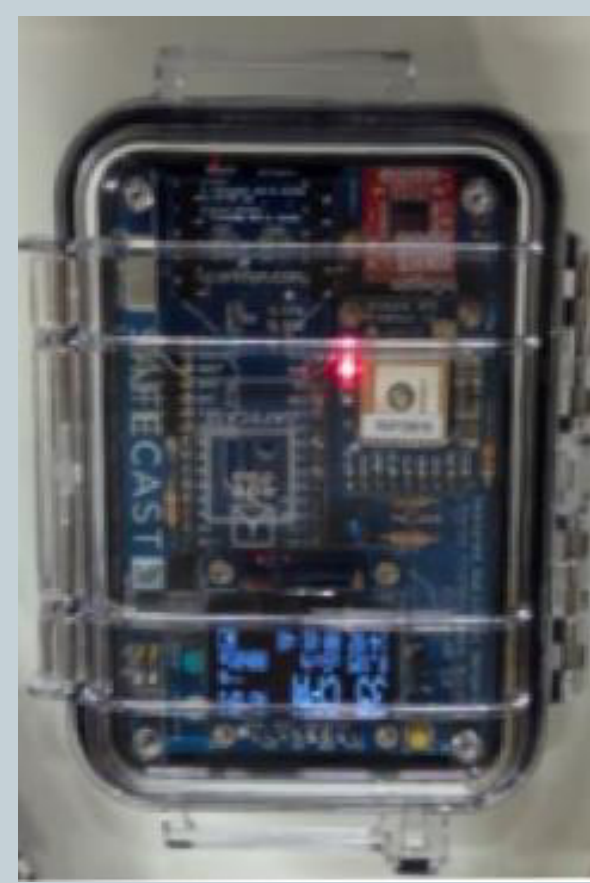

Specific interface: Safecast
Smart Radiation Detector Pocket Geiger (2) reddot
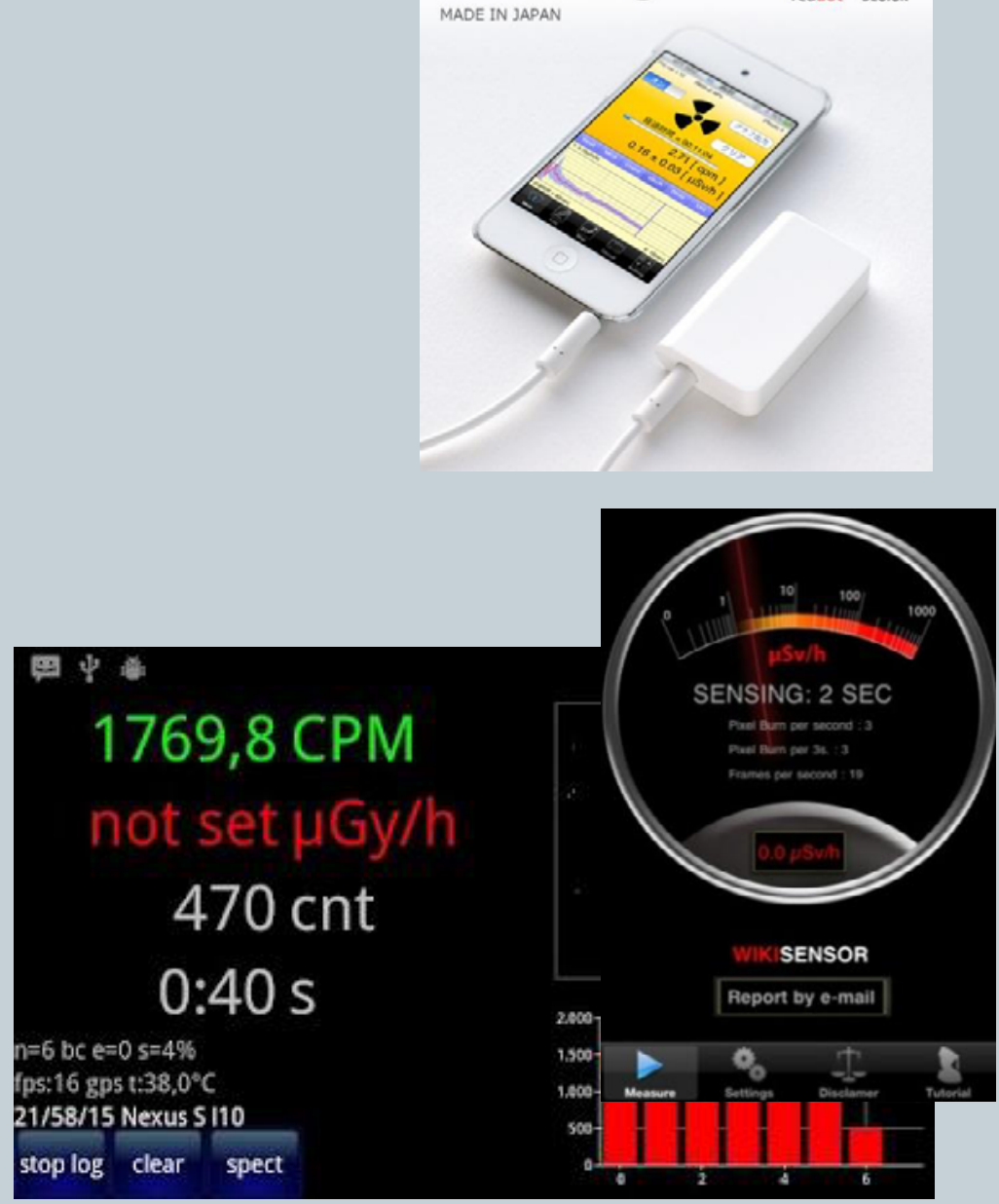


\section{Around the project today}

- Projects with students: Measurements with high schools from Vichy et Villeneuve-sur-Lot, project "Atom' investigation » with high schools from Perpignan et de Dieppe, contact with Fukushima high school...

- Contact with other collaborative projects: Safecast, D-Shutle...

- Presentation of the project to potential users in France: ANCCLI (local committees), Paris district... 


\section{Milestones and futures actions}

- February 2017: beta version available

- May-June 2017: site and dosimetric application available for the public

- 2017-2018: definition and implementation of protocols for data analysis

- 2017-2018: development of an application using the CMOS camera 


\section{Thank you for your attention}

ご清聴ありがとうございました 